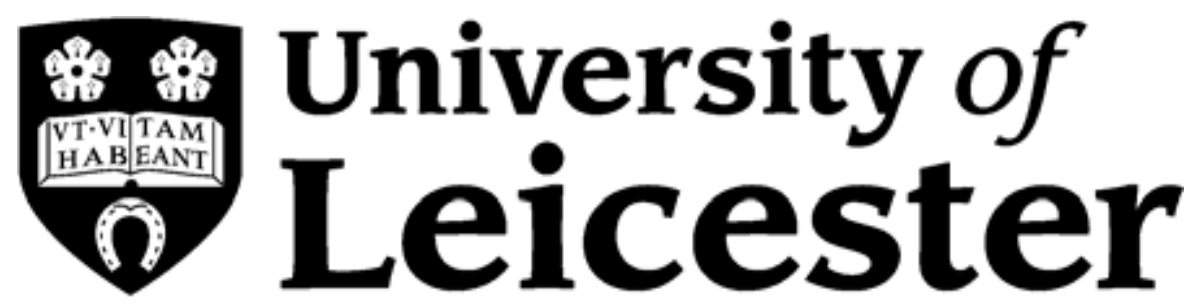

DEPARTMENT OF HEALTH SCIENCES

Working Paper No. 10/01

\title{
AGE CRITERIA FOR CERVICAL SCREENING IN ENGLAND: QUALITATIVE STUDY OF WOMEN'S VIEWS
}

\author{
Dr Natalie Armstrong (corresponding author) \\ Lecturer in Social Science Applied to Health \\ Department of Health Sciences $-2^{\text {nd }}$ Floor Adrian Building \\ University of Leicester, Leicester LE1 7RH \\ E-mail: na144@le.ac.uk
}

\begin{abstract}
Professor Mary Dixon-Woods
Professor of Medical Sociology

Department of Health Sciences

University of Leicester
\end{abstract}

Professor Elizabeth Murphy

Pro-Vice Chancellor and Head of College

College of Social Science

University of Leicester 


\title{
Age criteria for cervical screening in England: qualitative study of women's views
}

\begin{abstract}
The age criteria applied in the NHS Cervical Screening Programme have been much debated at policy and professional levels, but little is known about women's views on appropriate age criteria. Our objective is to provide insight into women's views on age criteria for the NHS Cervical Screening Programme in England. We present data collected as part of a qualitative interview study conducted in the East Midlands of England. Thirty-five women, representing a range of ages and ethnic groups, were interviewed. Analysis was based on the constant comparative method. Women's views about the age criteria that should appropriately be applied to cervical cancer screening diverged considerably from the technical principles and criteria upon which policy decisions are based. Women called for screening to be extended at both the upper and the lower ends of the age range. However, there was little explicit acknowledgement in women's accounts of the risks posed by screening or of the relative effectiveness and cost-effectiveness of screening in women of different ages. Policy decisions about screening programmes often face problems of legitimacy and acceptability. There is an increasingly pressing need to ensure that the criteria used to make decisions about who will be offered screening are made explicit and communicated effectively, so that people's views can be well-informed.
\end{abstract}




\section{Introduction}

England's screening programme for cervical cancer has, since 1988, sought to reduce cancer incidence and mortality by identifying pre-cancerous abnormalities that, if left untreated, could develop into invasive cervical cancer. Currently, women aged between 25 and 64 years are eligible for a free cervical screening test every three to five years. The programme's age criteria have proved controversial (Sasieni at al. 2009; Sasieni et al. 2003; Sasieni et al. 2006; Rieck et al. 2006; Raffle 2004). The age at which routine cervical screening should cease, including in particular whether it should be lowered to 50 years, has been much debated (Strander 2009; Rebolj et al. 2009), but currently remains age 64 . Until 2003, the age at which women were first invited for cervical screening ranged from 20-24 years depending on local policy. However, in 2003, the NHS Cervical Screening Programme (NHSCSP) in England standardised the age at which women are first invited for screening so that women now receive their first invitation at age 25 . This decision puts the English programme out of line with the three other countries of the UK, as Scotland, Wales and Northern Ireland all invite women from age 20.

The English decision to raise the age for first invitation to cervical screening was defended with reference to the rarity of the disease in women aged 20-24 and the lack of justification for the financial, psychosocial and morbidity costs of cervical screening in this age group (Sasieni et al. 2003). Recent evidence supports the conclusion that cervical screening in women aged $20-24$ is substantially less effective in preventing cancer than screening in older women (Sasieni et al. 2009), not least because changes in the young cervix 
are normal, and unnecessary treatment in response to putative abnormal features could interfere with fertility (Arbyn et al. 2008). Nonetheless, the decision to begin routine screening at 25 rather than 20 has been much debated, and in May 2009 an 'extraordinary meeting' of the Advisory Committee on Cervical Screening (ACCS) was asked to make recommendations to government ministers about whether the age 25 start date was still the right policy. The ACCS agreed unanimously there should be no change to the current policy, and explicitly rejected reducing the age limit to 20 years (Advisory Committee on Cervical Screening 2009).

Decisions about screening programmes still draw to a large extent on Wilson and Jungner's classic principles (Wilson and Jungner 1968). The UK's National Screening Committee has developed these principles into explicit criteria for appraising the viability, effectiveness and appropriateness of a programme (see Box 1) (National Screening Committee 2010).

\section{Box 1: National Screening Committee Criteria relating to the condition and the screening programme}

2. The epidemiology and natural history of the condition, including development from latent to declared disease, should be adequately understood and there should be a detectable risk factor, disease marker, latent period or early symptomatic stage.

15. The benefit from the screening programme should outweigh the physical and psychological harm (caused by the test, diagnostic procedures and treatment).

16. The opportunity cost of the screening programme (including testing, diagnosis and treatment, administration, training and quality assurance) should be economically balanced in relation to expenditure on medical care as a whole (i.e. value for money). Assessment against this criteria should have regard to evidence from cost benefit and/or cost effectiveness analyses and have regard to the effective use of available resource.

21. Public pressure for widening the eligibility criteria for reducing the screening interval, and for increasing the sensitivity of the testing process, should be anticipated. Decisions about these parameters should be scientifically justifiable to the public. 
However, public controversy in relation to screening programmes is rarely absent, and the high-profile death of the celebrity Jade Goody at the age of 27 in 2009, has led to considerable pressure for a re-lowering of the starting age for cervical screening. This pressure has endured after the ACCS review, and in June 2010 the family of Claire Allen, who died of cervical cancer at the age of 23 years, presented a petition to Downing Street calling for the screening age to be lowered (Department of Health 2010).

It is important to understand women's views on the appropriate age range for cervical screening and the reasons for such views, as they are likely to be critical in achieving public acceptability, and perceived legitimacy, of policy decisions in relation to screening programmes. There is, however, little research in this area. In this paper, we report data from a qualitative study of women's understandings and experiences of cervical screening in order to explore how women view the issue of appropriate age criteria, including both the upper and lower limits. The data for this study were collected before the decision to standardise age of first invitation across England, and thus give insights into women's views in a situation where they potentially had the option of attending screening from age 20.

\section{Methods}

This paper draws on a qualitative interview study carried out in the East Midlands of England. Ethical approval for the project was received from the University of Nottingham and all participants gave their informed consent to take part in the study. The interviews were carried out in $2002 / 3$, and so were conducted immediately prior to the decision to standardise the starting age at 25 years. Thus, at the time the interviews were conducted, the arrangements 
for routine cervical screening were an invitation every three years or five years (depending on the local area) between the ages of 20 and 64 years, and women from across this age range were eligible to participate in the study.

A purposive sampling approach, structured by age and ethnicity, was employed to ensure heterogeneity (see Table 1).

Table 1: Sample $($ Total $=35)$

\begin{tabular}{|l|l|l|l|}
\hline Ethnic group & $\mathbf{2 0 - 3 4}$ years & $\mathbf{3 5 - 4 9}$ years & $\mathbf{5 0 - 6 4}$ years \\
\hline White British & 4 & 4 & 5 \\
\hline South Asian & 4 & 4 & 3 \\
\hline African Caribbean & 4 & 4 & 3 \\
\hline
\end{tabular}

Participants were recruited through community groups (such as local women's groups, community organisations and religious groups) and snowball sampling (Arber 2001). The sample was structured by age and ethnic background because of evidence that variations in ethnic, cultural or religious group influence understandings of health and illness and experiences of health care (Curtis and Lawson 2000; Higginbottom 2000; Naeem 2003; Sutton et al. 2001; Underwood et al. 1999). The local population was predominantly White British, South Asian and African Caribbean (National Statistics 2004). Eighteen of the 35 participants were from higher socioeconomic groups (defined as 1, 2 and 3 non-manual) and 23 were married. Semi-structured interviews lasting approximately one hour took place in the women's homes or community group premises. An interpreter was used for three interviews with older South Asian women. Participants were invited to talk about their experiences and perspectives on cervical screening and cancer. An interview guide, identifying a number of broad topics, was used to ensure coverage of key areas identified in advance of the data collection, but 
no attempt was made to restrict the interviews to these topics or to control the order in which they were discussed. It was important to avoid the women feeling they were being 'tested' on their knowledge of cervical screening, causing unnecessary anxiety and/or fear of saying something 'wrong'.

All interviews were audio-recorded and fully transcribed. Analysis of the interview material was based upon the constant comparative method (Glaser and Strauss 1967). Key themes within the data were identified through repeated close readings and annotation of the interview transcripts. Individual transcripts were compared and contrasted, and deviant cases identified and explored. A coding framework was developed and refined, and subsequently applied to the full data set. QSR NVivo software was used to aid the coding, management and retrieval of data. The illustrative quotes included below were selected as particularly clear and/or concise examples, and all names have been changed.

\section{Results}

The 35 participants all reported routinely receiving an invitation letter to attend for cervical screening. Twenty-six of the 35 women interviewed reported attending for screening regularly; one had never attended; and the remainder could be characterised as 'sporadic attenders'. Their accounts suggested that their views of the appropriate age range for cervical screening diverged considerably from the technical principles and criteria upon which policy decisions are based.

\section{Lower age limit}


Thirty of the participants identified the leaflet, entitled "Cervical Screening:

The Facts" (which accompanies screening invitations) as a key source of their information about the programme (Department of Health 2002). The leaflet explained the purpose of screening, outlined testing and reporting procedures, and identified factors that may make cervical cancer more likely (Box 2).

\section{Box 2: Explanation of factors that may make cervical cancer more likely}

Should all women have the test?

We offer the test to all women aged between 20 and 64 but cervical cancer is more common if you:

- first had sex at an early age;

- smoke;

- do not use condoms;

- have had several sexual partners or have had a partner who has

- had several other partners; or

- take immunosuppressant drugs (for example, after an organ transplant).

It strongly emphasised sexual activity as a key risk factor (Armstrong and Murphy 2008). For participants in our study, it was sexual activity rather than age that they saw as the appropriate determinant of whether women should be invited to screening.

I think the ones who are sexually active should go.

(Doreen, African Caribbean, 50-64 years)

Participants suggested that women should begin attending for screening as soon as they became sexually active, as this would be responsible behaviour. Thus, participants suggested screening should be available (and indeed encouraged) from a significantly earlier age than recommended - as soon as sexual activity began. There were suggestions that professionals and policymakers were being naïve or out of touch in failing to recognise the age at which sexual activity may start: 
Well probably now that people are having sex at...'cos it is, it's more likely if you're obviously active in sex isn't it...so the amount of young girls that you hear of that get pregnant at 13, 14, 15, 16. It probably would be better to start it at a younger age now like 16. 'Cos I think that there are an awful lot of girls, I mean that you read in the papers, 'cos there are an awful lot of girls that are active, so I think 16 would be the age.

(Abigail, White British, 20-34 years)

I think maybe we should reduce it, and I think maybe if a doctor or Family Planning Clinic...knew that a young girl was sexually active, be it from 12 or whatever... maybe it should be a matter of fact that they go on the register to be screened because obviously it is quite a long time (referring to the time between becoming sexually active and a first screening).

(Julia, White British, 35-49 years)

\section{Upper age limit}

The equation between being sexually active with needing screening was similarly applied in women's accounts to the upper age limit. It was often assumed that routine screening provision ceased, at least in part, because of an official perception that older women are no longer sexually active, or at least not to the same degree as their younger counterparts:

'Cos like a lot of 64 year olds probably still have a husband and an active sex life and that and, yeah, so probably it would be better to do it until they're older. Why have an age limit on it if you're a woman and you've got an active sex life then why put an age limit on it...64 isn't 
like years ago, 64 was classed as being old, but 64, but it's not actually. I mean in your 80's now you are not actually classed as old, it's not until you get to your 90's now that you are classed as old. (Abigail, White British, 20-34 years)

I think age is ridiculous because everybody's body is different, you know, metabolism is different. No there certainly shouldn't be a cut off age for anything I don't think.

(Alice, White British, 35-49 years)

\section{Perception of risks, effectiveness and cost-effectiveness}

Participants' accounts were examined for evidence that women identified risks, effectiveness, and cost-effectiveness as important influences on their views about who should be offered screening. Women's accounts suggested that they understood the screening programme entirely in terms of its benefits and they did not perceive that the effectiveness of the programme would vary by age. Participants characterised attendance at screening as morally responsible behaviour. Their strong perception was that the state was obliged to fulfil its side of the bargain by providing the programme, to the extent that considerations of cost-effectiveness in relation to age were seen as illegitimate:

But just to dismiss you at 64 and therefore you are old enough to die anyway seems to be the message that might be coming across. And I don't think that that's necessarily right. It might be funding that that's the only amount that they can afford to put in and so they have to put in limitations somewhere so, if that's the case then I understand that but it doesn't necessarily mean that it's right. 
(Audrey, White British, 50-64 years)

Well I don't know why 64? Everyone is so different anyway 64 seems such a random age to pick to stop screening... why is it suddenly so different from 63 to 65 ? What's changed? The only thing that I could say was that they had decided by that age it is not worth spending any more money on you because you're over the hill anyway, but 64 seems such a weird age to pick.

(Selma, White British, 20-34 years)

\section{Discussion and conclusions}

Decisions about the most appropriate age group for inclusion in the NHS Cervical Screening Programme are focused around technical criteria including those relating to incidence and natural history of cervical abnormalities, the relative effectiveness and cost-effectiveness of screening in women of different age groups and the weight of possible benefits against potential harms. Our data suggest that women's views of appropriate age criteria differ markedly from these technical principles. Women's accounts appeared to focus solely on benefits of screening and were strongly linked with the view that the most important risk factor was sexual activity, regardless of age. There was little evidence that women recognised that screening also poses the risk of harms of physical and psychological morbidity. Similarly, the effectiveness of screening in different age groups was not discussed, and considerations of cost-effectiveness in relation to age were perceived as unacceptable. Women's views about the attractiveness of screening meant that they supported a wider age range than current official policy sees as appropriate. 
The data presented here demonstrate how, in the absence of explicit statements in routine information material about why screening is focused on a particular age range, women developed and advanced alternative explanations for why screening was not offered to women outside this range. They believed that failure to offer routine screening was based on a pennypinching attitude and official naiveté about sexual behaviour. These alternative explanations draw on very different criteria and kinds of evidence from those used by policy-makers.

Our findings highlight some of the shortcomings and dilemmas in communicating with the public about screening programmes. In order to encourage attendance, official information leaflets may emphasise the benefits and modifiable risk factors, and give little attention to potential harms and risks of screening or variability in effectiveness of screening according to age and other criteria (Thornton et al. 2003; Gøtzsche et al. 2009). But promoting the idea that attendance at screening is a feature of responsible health behaviour means that people may find it difficult to reconcile the positive aspects of screening with the fact that screening is only routinely offered to women within a particular age range. They may well, as women in our study suggested, see age criteria as an illegitimate and unjustifiable denial of amenity.

The concerns expressed by women in this study are likely to have intensified rather than lessened since the data were collected. The leaflet entitled "Cervical Screening: The Facts" remains virtually unaltered since these interviews were conducted, save that a bullet point advising that cervical cancer is more common if women do not use condoms has been omitted from 
the current version. Despite the policy changes in standardising age of first invitation, the leaflet provides no rationale for the age criteria used in the programme, and continues to emphasise sexual activity as a risk factor. It includes the statement that cervical cancer is more common in women who first had sex at an early age, and thus does little to counter the views of women in our study that screening should be matched to age of sexual activity. At the same time, the Jade Goody effect is likely to have contributed to the development of a widely-held availability heuristic, where people predict the frequency of an event (such as cervical cancer affecting a young woman) based on how easily an example can be brought to mind. The presentation to Downing Street in June 2010 of a petition calling for the starting age to be lowered provides some evidence of this.

\section{Strengths and limitations of the study}

This was a small study that makes no claims to representativeness; a survey approach would be needed to quantify frequency of the views expressed. The study was conducted prior to the decision to standardise the lower age for screening at 25 years, and this may be seen as both a weakness (in the sense that the data were collected some time ago), but a strength in the sense that these women had experience of different systems, and thus not only offer comments from a position of a wider perspective but also demonstrate the striking uniformity of their views.

\section{Implications for future research or clinical practice}

Given that debates about medical screening are rarely confined to policymakers and health professionals, but increasingly enter the public sphere, there is an increasingly pressing need to ensure that the criteria used to make 
decisions about who will be offered screening are made explicit and properly communicated in order to establish the legitimacy and acceptability of such policy decisions. If this does not happen, contestation and agitation can be anticipated, and there is a risk that public pressure could overwhelm carefully considered scientific criteria. Understanding how women make sense of who is invited for screening is an important first step in thinking about how best to communicate such decisions to the public. 


\section{References}

Advisory Committee on Cervical Screening., 2009. Minutes of extraordinary meeting to re-examine current policy on cervical screening for women aged 20-24 years taking account of any new evidence and to make recommendations to the National Cancer Director and Ministers. Available at: http://www.cancerscreening.nhs.uk/cervical/cervical-review-minutes20090519.pdf

Arber, S., 2001. Designing samples. In: N. Gilbert, ed. Researching Social Life (2nd ed) London: Sage, 58-82.

Arbyn, M. Kyrgiou, M. Simoens, C. et al., 2008. Perinatal mortality and other severe adverse pregnancy outcomes associated with treatment of cervical intraepithelial neoplasia: meta-analysis. British Medical Journal, 337,a1284.

Armstrong, N. and Murphy E., 2008. Weaving meaning? An exploration of the interplay between lay and professional understandings of cervical cancer risk. Social Science and Medicine, 67,1074-1082.

Curtis, S. and Lawson, K., 2000. Gender, ethnicity and self-reported health: the case of African-Caribbean populations in London. Social Science and Medicine, 50,365-385.

Department of Health. 2002. Cervical screening: The facts. London: Department of Health.

Department of Health, 2010.

http://www.dh.gov.uk/en/MediaCentre/Statements/DH_116591 (accessed 5th July 2010)

Glaser, B. and Strauss, A., 1967. The Discovery of Grounded Theory. Chicago: Aldine. 
Gøtzsche, P.C. Hartling, O.J. Nielsen, M. et al., 2009. Breast screening: the facts—or maybe not. British Medical Journal, 338:b86.

Higginbottom, G., 2000. Heart health-associated health beliefs and behaviours of adolescents of African and African Caribbean descent in two cities in the United Kingdom. Journal of Advanced Nursing, 32,1234-1242.

Naeem, A.G., 2003. The role of culture and religion in the management of diabetes: a study of Kashmiri men in Leeds. The Journal of the Royal Society for the Promotion of Health, 132,110-116.

National Screening Committee, 2010. http://www.screening.nhs.uk/criteria (accessed 9th March 2010)

National Statistics. 2004. http://neighbourhood.statistics.gov.uk/ (accessed 15th September 2004)

Raffle, A.E., 2004. Editorial: Cervical screening. British Medical Journal, 328,1272-3.

Rebolj, M. van Ballegooijen, M. Lynge, E. et al., 2009. Incidence of cervical cancer after several negative smear results by age 50: prospective observational study. British Medical Journal,338,b1354.

Rieck, G.C. Tristram, A. Hauke, A. et al., 2006. Cervical screening in 20-24 years olds. Journal of Medical Screening, 13,64-71.

Sasieni, P. Adams, J. and Cuzick, J., 2003. Benefit of cervical screening at different ages: evidence from the UK audit of screening histories. British Journal of Cancer, 89,88-93.

Sasieni, P. Castanon, A. and Cuzick. J., 2009. Effectiveness of cervical screening with age: population based case-control study of prospectively recorded data. British Medical Journal, 339,b2968. 
Sasieni, P. Kitchener, H. Patnick, J. et al., 2006. Cervical screening in 20-24 year olds. Journal of Medical Screening, 13,62-63.

Strander, B., 2009. At what age should cervical screening stop? British Medical Journal, 338,b809.

Sutton, G.C. Storer, A. and Rowe, K., 2001. Cancer screening coverage of south Asian women in Wakefield. Journal of Medical Screening, 8:183-6.

Thornton, H. Edwards, A. and Baum, M., 2003. Women need better information about routine mammography. British Medical Journal, 327:101-3.

Underwood, S.M. Shaikha, L. and Bakr, D., 1999. Veiled yet vulnerable: breast cancer screening and the Muslim way of life. Cancer Practice, 7,285290.

Wilson, J.M.G. and Jungner, G., 1968. Principles and practice of screening for disease. Public health paper No. 34. Geneva: World Health Organisation. Available at: http://www.who.int/bulletin/volumes/86/4/07-050112BP.pdf 